\title{
Suicide Inactivation of the Flavoenzyme D-Lactate Dehydrogenase by $\alpha$-Hydroxybutynoate ${ }^{\dagger}$
}

\author{
Steven T. Olson, Vincent Massey,* Sandro Ghisla, and Carolyn D. Whitfield
}

\begin{abstract}
The acetylenic $\alpha$-hydroxy acid 2-hydroxy-3butynoate $(\alpha \mathrm{HB})$ is a substrate and an irreversible inactivator of the FAD-containing flavoenzyme D-lactate dehydrogenase from Megasphaera elsdenii. On the average, the enzyme undergoes five catalytic turnovers with $\alpha \mathrm{HB}$ in air at $\mathrm{pH} 7.0$ before being inactivated. Irreversible inactivation is due to the conversion of the flavin to a pink adduct with visible absorption peaks at 522, 382, and $330 \mathrm{~nm}$ and weak fluorescence with an emission maximum at $635 \mathrm{~nm}$. The adduct is stable and can be released from the enzyme and purified. It retains a structure analogous to FAD since it binds to the FAD-specific apo-D-amino acid oxidase. It can be further converted to an FMN analogue with phosphodiesterase
\end{abstract}

\begin{abstract}
A cetylenic suicide substrates were first used by Bloch and his co-workers, who found that $\beta$-hydroxydecanoylthioester dehydrase was irreversibly inactivated by a $\beta$-acetylenic substrate analogue (Bloch, 1971). This inactivation was shown to result from an enzyme-catalyzed rearrangement of the acetylenic function to a reactive allene, which then alkylated an active-site histidine. Since the enzyme had caused its own destruction, the acetylenic substrate was appropriately called a suicide substrate.

Since then, several other enzymes have been demonstrated to be irreversibly inactivated by acetylenic suicide substrates in a like manner (Walsh, 1977). Such studies have provided indirect evidence for carbanionic intermediates in the normal enzyme-catalyzed reactions. Thus, the formation of a carbanion adjacent to an acetylenic function would be expected to promote the rearrangement to a reactive allene which can then serve as an active-site alkylating agent.

In the case of several flavin enzymes which catalyze dehydrogenation reactions, acetylenic substrates were also found to cause irreversible inactivation. Instead of alkylating the protein, however, these suicide inhibitors were found to covalently attach to the flavin coenzyme. A few cases were found in which alkylation of the protein by the acetylenic suicide substrate occurred (Walsh, 1977, 1978).

Two different types of covalent suicide inhibitor-flavin adducts have been described. With monoamine oxidase,

\footnotetext{
${ }^{\dagger}$ From the Department of Biological Chemistry, The University of Michigan, Ann Arbor, Michigan 48109 (S.T.O., V.M., and C.D.W.), Germany (S.G.). Received March 1, 1979; revised manuscript received June 20,1979. This work was supported by a grant from the U.S. Public Health Service, GM 11106, to V.M. and by a grant from the Deutsche
} and Fachbereich Biologie der Universität Konstanz, D775 Konstanz, West Forschungsgemeinshaft to S.G.
\end{abstract}

which binds to the FMN-specific apoflavodoxin. Experiments were conducted to test whether inactivation was initiated by an $\alpha \mathrm{HB}$ allene carbanion or the dehydrogenation product of $\alpha H B$. Kinetic studies proved inconclusive in that a rapid equilibrium between an oxidized enzyme-allene carbanion pair and reduced enzyme-keto acid pair would make these two species kinetically equivalent. The olefinic substrate 2hydroxy-3-butenoate, however, produced no flavin adduct. Since the keto acid derived from the oxidation of this $\alpha$ hydroxy acid is expected to be as reactive as 2-keto-3-butynoate, it is concluded that an allene carbanion produced by abstraction of the $\alpha$-hydrogen of $\alpha \mathrm{HB}$ is the reactive species which covalently adds to the flavin.

covalent addition at position N(5) occurred (Maycock et al., 1976), and with the L-specific lactate oxidase, cyclic addition to $N(5)$ and $C(4 a)$ of the flavin nucleus was found (Walsh et al., 1972; Ghisla et al., 1976; Schonbrunn et al., 1976). Since these positions of the flavin coenzyme are electrophilic in the oxidized state, an attack of an electrophilic allene is considered unlikely. Either an allene carbanion or the oxidized acetylenic substrate is considered a potential inactivating species (Walsh, 1977, 1978). Studies of these suicide reactions have thus focused on discriminating between these two possible inactivation pathways with the intent of discerning the involvement of carbanions in these flavoenzymes.

The flavoenzyme D-lactate dehydrogenase from the anaerobic bacterium Megasphaera elsdenii (formerly known as Peptostreptococcus elsdenii) catalyzes the oxidation of D-lactate to pyruvate, an electron transferring flavoprotein (ETF) serving as the natural electron acceptor (Brockman, 1971; Brockman \& Wood, 1975). The enzyme has been purified to homogeneity and shown to be specific for the $D$ isomer of lactate and to contain 1 equiv each of FAD and zinc per mol of protein subunit (Olson \& Massey, 1979).

The production of a stereochemically precise $\mathrm{N}(5)-\mathrm{C}(4 \mathrm{a})$ cyclic flavin adduct upon reaction of $\alpha$-hydroxybutynoate $(\alpha \mathrm{HB})^{\mathrm{i}}$ with the L-specific lactate oxidase (Walsh et al., 1972; Schonbrunn et al., 1976) prompted the investigation of the reaction of $\alpha \mathrm{HB}$ with the $\mathrm{D}$-specific lactate dehydrogenase.

\footnotetext{
1 Abbreviations used: $\mathrm{ApAD}^{+}, 3$-acetylpyridine adenine dinucleotide, oxidized form; DCIP, 2,6-dichloroindophenol; $\mathrm{Cl}_{3} \mathrm{AcOH}$, trichloroacetic acid; DTT, dithiothreitol; TLC, thin-layer chromatography; ETF, electron transfer flavoprotein; LDH, lactate dehydrogenase (pyridine nucleotide dependent); DAAO, D-amino acid oxidase; $\alpha \mathrm{HB}, 2$-hydroxy-3-butynoate; $\alpha \mathrm{KB}, 2$-keto-3-butynoate.
} 
$\alpha \mathrm{HB}$ did indeed cause irreversible inactivation of the enzyme accompanied by the formation of a new type of flavin adduct. With L-lactate oxidase a study of the suicide reaction did not allow an unequivocal choice between the two plausible inactivation mechanisms (Ghisla et al., 1976). It was hoped that the different chemistry involved in producing the novel flavin adduct with D-lactate dehydrogenase might resolve this issue.

This paper details the reaction of $D$-lactate dehydrogenase with the acetylenic substrate $\alpha \mathrm{HB}$ and some of the properties of the chemically modified flavin. The following paper (Ghisla et al., 1979) focuses on the elucidation of the structure of the modified flavocoenzyme.

\section{Materials and Methods}

Materials. D-Lactate dehydrogenase was isolated from $M$. elsdenii by the procedure given in the preceding paper (Olson \& Massey, 1979). Enzyme concentrations were determined by using an extinction coefficient at $454 \mathrm{~nm}$ for enzyme-bound FAD of $12800 \mathrm{M}^{-1} \mathrm{~cm}^{-1}$ at $20^{\circ} \mathrm{C}$. FAD, FMN, DCIP, $\mathrm{NADH}, \mathrm{NAD}^{+}$, rabbit muscle LDH, sodium pyruvate, dithiothreitol, and Naja naja snake venom phosphodiesterase were all from Sigma Chemical Co. FAD was further purified by DEAE-cellulose chromatography (Massey \& Swoboda, 1963), and FMN was purified by affinity chromatography with an apoflavodoxin column (Mayhew \& Strating, 1975). D-Lactate (lithium salt) was from Calbiochem, ApAD ${ }^{+}$was from P-L Biochemicals, and silica gel $G$ plates were from Brinkman Instruments. Sephadex G-25 medium and superfine grades were from Pharmacia. 5-Deazariboflavin was a gift from Dr. P. Hemmerich. Vinylglycollate and $\alpha \mathrm{HB}$ were gifts from Dr. C. Walsh. Alternatively, $\alpha \mathrm{HB}$ was synthesized by published procedures (Leonard, 1956; Verny \& Vessiere, 1967). Resolved $\mathrm{D}-\alpha \mathrm{HB}$ and $\mathrm{L}-\alpha \mathrm{HB}$ were obtained by fractional crystallization of the brucine salts (Fendrich and Ghisla, unpublished experiments). All other chemicals were of the best grades commercially available. Other flavoproteins were isolated and their apoproteins obtained by published procedures: flavodoxin (Mayhew, 1971; Mayhew \& Massey, 1969) and D-amino acid oxidase (Curti et al., 1973; Massey \& Curti, 1966). Spectrophotometric instrumentation, enzyme assays, and anaerobic techniques were the same as those described in the preceding paper (Olson \& Massey, 1979).

Preparation and Purification of the Pink Flavin Adduct. D-Lactate dehydrogenase $(1-2 \mu \mathrm{mol})$ in $5 \mathrm{~mL}$ of $0.1 \mathrm{M} \mathrm{KP}_{\mathrm{i}}$, pH 6.0, plus $1 \mathrm{mM}$ DTT was incubated anaerobically with 2-10 mM DL- $\alpha \mathrm{HB}$ for several days at room temperature to produce the pink flavin adduct. It was then opened to air and passed through a small Sephadex G-25 column $(40-\mathrm{mL}$ bed volume) in distilled water to remove unreacted acetylenic acid and buffer. To the pooled protein fractions cold $50 \%(\mathrm{w} / \mathrm{v})$ $\mathrm{Cl}_{3} \mathrm{AcOH}$ was added to a final concentration of $5 \%$, precipitating the protein and releasing the bound flavin into solution. After centrifugation, the precipitate was washed once with $5 \% \mathrm{Cl}_{3} \mathrm{AcOH}$ and centrifuged again, and the two supernatants were combined. $\mathrm{Cl}_{3} \mathrm{AcOH}$ was then removed by extraction several times with a total of $\sim 10$ volumes of cold ether, and the solution was neutralized with $0.1 \mathrm{M} \mathrm{Na}_{2} \mathrm{CO}_{3}$ to a $\mathrm{pH}$ of 6-7. The pink solution was concentrated under reduced pressure to a small volume $(\sim 2 \mathrm{~mL})$ and applied to a $2.5 \times 100 \mathrm{~cm}$ column of Sephadex G-25 superfine equilibrated in distilled water and run at $\sim 5$ drops $/ \mathrm{min}$. A pink band moved gradually down the column leaving a yellow band behind (unreacted FAD). The pink fractions were pooled and taken to dryness under reduced pressure. After taking up in a very small volume of water, the solution was applied as a thin band to a $20 \times 20 \mathrm{~cm}$ preparative silica gel plate $(1-\mathrm{mm}$ thickness) and run in $6 \%(w / v) \mathrm{Na}_{2} \mathrm{HPO}_{4} \cdot 12 \mathrm{H}_{2} \mathrm{O}$ to at least a $15-\mathrm{cm}$ height. Highly fluorescent flavin impurities were clearly separated from a major dark pink band with pink fluorescence which was scraped from the plate and eluted several times with $\sim 5-\mathrm{mL}$ portions of water. The eluate was concentrated to dryness and taken up in a small volume of water.

Preparation of the Adduct at the FMN Level. Pink FMN was obtained by addition of a concentrated potassium phosphate buffer to the pink FAD in water to a final concentration of $0.1 \mathrm{M}$ and a $\mathrm{pH}$ of 7.0. A few grains of snake venom phosphodiesterase were added, and the splitting of AMP from the pink FAD was monitored by a decrease in its pink fluorescence (excitation wavelength 520-600 nm; emission wavelength $635 \mathrm{~nm}$ ). When the fluorescence changes were complete, the solution was applied to an apoflavodoxin column (Mayhew \& Strating, 1975) equilibrated in $0.1 \mathrm{M}$ potassium phosphate, $\mathrm{pH} 7.0$, at $4^{\circ} \mathrm{C}$. A concentrated pink band with pink fluorescence formed at the top of the column. The column was then washed with several volumes of water to remove buffer, AMP, and snake venom protein. The pink FMN was eluted with $5 \%(\mathrm{w} / \mathrm{v}) \mathrm{Cl}_{3} \mathrm{AcOH} . \mathrm{Cl}_{3} \mathrm{AcOH}$ was removed from the pink flavin fractions by extraction several times with a total of 10 volumes of cold ether. The $\mathrm{pH}$ was adjusted to between 6 and 7 with $0.1 \mathrm{M} \mathrm{Na}_{2} \mathrm{CO}_{3}$, and the sample was evaporated to dryness under reduced pressure and then taken up in water.

Standardization of Apoprotein Concentrations Used for Pink Flavin Binding Studies. The concentrations of the apoprotein stock solutions of D-amino acid oxidase, specific for FAD (McCormick et al., 1964), and flavodoxin, specific for FMN (Mayhew, 1971), were determined as follows. Purified FAD or FMN $(1-10 \mu \mathrm{M})$ in a suitable buffer $(0.1$ $\mathrm{M}$ sodium pyrophosphate, $\mathrm{pH} 8.5$, for $F A D$ and $0.1 \mathrm{M} \mathrm{KP}_{\mathrm{i}}$, $\mathrm{pH} 7.0$, for FMN) was titrated with increments of a concentrated apoprotein solution $\left[(1-10) \times 10^{-4} \mathrm{M}\right]$ at $20^{\circ} \mathrm{C}$. The binding of flavin to both these apoproteins is accompanied by a significant quenching of the flavin fluorescence (Massey et al., 1966; Mayhew, 1971) which was monitored by exciting at $450 \mathrm{~nm}$ and observing the emission at $525 \mathrm{~nm}$. Additions were continued, allowing enough time after each addition for the fluorescence changes to occur, until no further fluorescence changes occurred, signaling the end point. With DAAO, 1 $\mathrm{mM}$ benzoate was included to ensure tight binding (Massey et al., 1966). Since binding is tight for both apoproteins, at the end point a stoichiometric amount of apoprotein must have been added, allowing a calculation of the concentration.

\section{Results}

$\alpha H B$ as Both an Irreversible Inactivator and a Substrate for D-Lactate Dehydrogenase. $\alpha \mathrm{HB}$ causes a time-dependent loss in the catalytic activity of D-lactate dehydrogenase (Figures 1 and 2). In the experiment shown in Figure 1, $\alpha \mathrm{HB}$ produced a gradual loss in the enzyme's catalytic activity over the course of ca. $600 \mathrm{~min}$. The rate at which this inactivation occurred could be increased by increasing the $\alpha \mathrm{HB}$ concentration (see further section) and was completely dependent upon the presence of $\alpha \mathrm{HB}$.

Spectral changes in the enzyme associated with the inactivation (see Formation of a Pink Chromophore on Reaction with $\alpha \mathrm{HB}$ ) were stable and unchanged after passage through a Sephadex G-25 column or dialysis to remove excess inactivator. Thus, the inactivation is irreversible.

$\alpha \mathrm{HB}$ is also a substrate for the enzyme. When added to enzyme in the presence of ferricyanide or DCIP, both good electron acceptors for the enzyme (Olson \& Massey, 1979), 


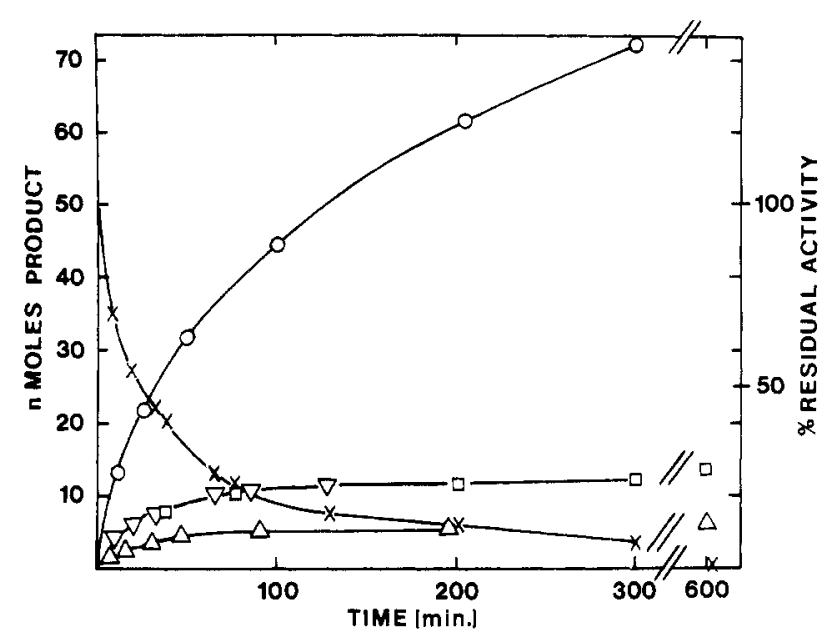

FIGURE 1: Course of inactivation and turnover of D-lactate dehydrogenase by $\alpha \mathrm{HB}$. Enzyme $(13.7 \mu \mathrm{M})$ was reacted with $500 \mu \mathrm{M}$ $\mathrm{DL}-\alpha \mathrm{HB}$ in an air-saturated solution of $0.1 \mathrm{M} \mathrm{KP}, \mathrm{pH} 7.0$, at $20^{\circ} \mathrm{C}$. The inactivation was monitored by recording spectra and removing aliquots for assay of residual activity at varying times. Pink flavin was determined from the $540-\mathrm{nm}$ absorbance by using an $\epsilon_{540}=5880$ $\mathrm{M}^{-1} \mathrm{~cm}^{-1}$ (see further section). Turnover was measured by including $100 \mu \mathrm{g} / \mathrm{mL}$ rabbit muscle LDH and $190 \mu \mathrm{M} \mathrm{NADH}$ in the reaction and following the loss in $340 \mathrm{~nm}$. After correction for the background destruction of NADH, the net nanomoles of NADH oxidized were obtained (by using an $\epsilon_{340}=6220 \mathrm{M}^{-1} \mathrm{~cm}^{-1}$ ) which equals the nanomoles of $\alpha \mathrm{KB}$ produced ( $\mathrm{cf}$. Scheme I). (O) represents nanomoles of $\alpha \mathrm{KB} ;(\square)$ and $(\nabla)$ represent nanomoles of inactive enzyme in the presence or absence, respectively, of rabbit LDH and NADH (assuming activity loss is proportional to enzyme flavin reacted); $(\Delta)$ represents nanomoles of pink flavin. The crosses are the activity data plotted as the percent residual activity.

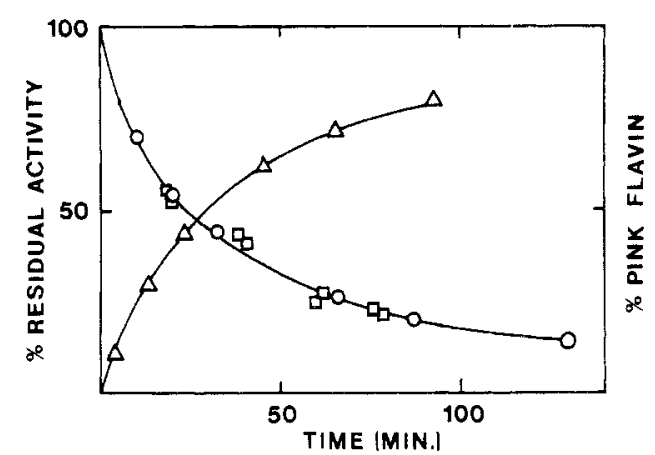

FIGURE 2: Correlation between activity loss and pink flavin formation in the anaerobic inactivation of D-lactate dehydrogenase by $\alpha \mathrm{HB}$ and the effect of oxygen on the inactivation rate. Enzyme $(15.0 \mu \mathrm{M})$ was reacted with $420 \mu \mathrm{M}$ DL- $\alpha \mathrm{HB}$ in $0.1 \mathrm{M} \mathrm{KP}$, pH 7.0 , at $20^{\circ} \mathrm{C}$, anaerobically. Pink flavin formation, represented by the triangles, was followed by monitoring the $540-\mathrm{nm}$ absorbance and is expressed as the percent of that formed in 1 day. To monitor the activity losses anaerobically (represented by the squares), we ran a series of identical reactions and, after varying times, opened them under nitrogen and withdrew aliquots for assay. The aerobic reaction was performed under identical conditions in an air-saturated solution, and the activity losses (represented by the circles) were monitored by periodically withdrawing aliquots for assay.

the acceptors are reduced, the reduction rate falling off with time due to progressive inactivation. When $\alpha \mathrm{HB}$ is mixed with enzyme containing NADH and rabbit muscle L-LDH, NADH oxidation is observed. This indicates that the expected oxidation product, $\alpha$-ketobutynoate ( $\alpha \mathrm{KB}$ ), is produced by normal catalytic turnover, oxygen serving as the electron acceptor (Scheme I).

The latter system was used to quantitate the number of turnovers occurring during the course of inactivation in airsaturated buffer. In Figure 1 is shown an experiment in which both enzyme inactivation and $\alpha \mathrm{HB}$ turnover were simulta-
Scheme I

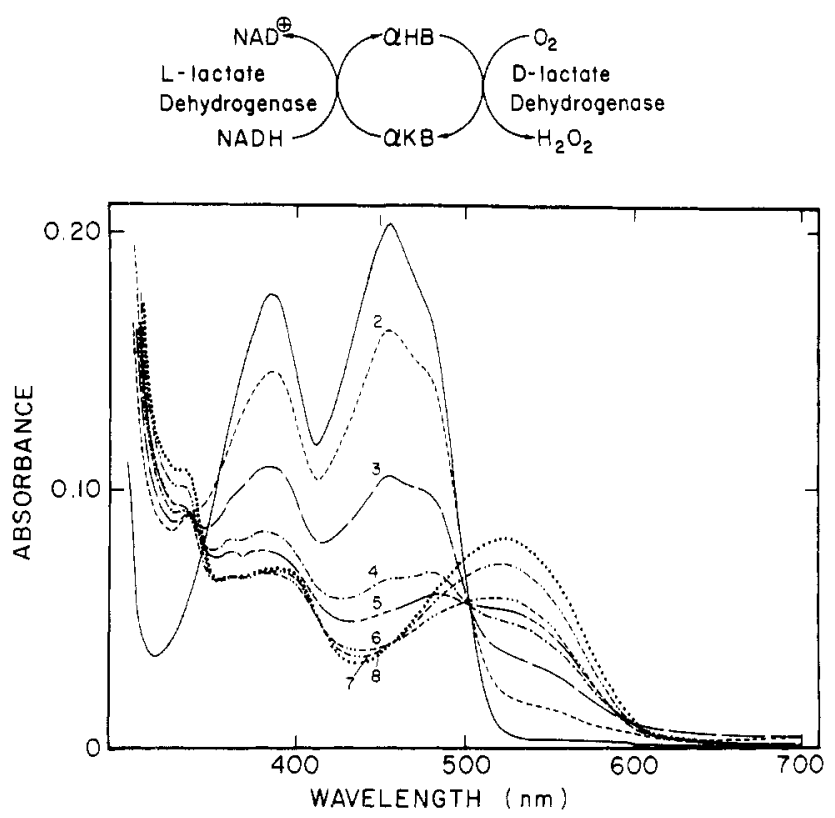

FIGURE 3: Spectral course of the anaerobic reaction of $\alpha \mathrm{HB}$ with D-lactate dehydrogenase. Enzyme $(15.3 \mu \mathrm{M})$ in $0.1 \mathrm{M} \mathrm{KP}_{\mathrm{i}}, \mathrm{pH} 7.0$, containing $1 \mathrm{mM}$ DTT was reacted with $730 \mu \mathrm{M}$ DL- $\alpha \mathrm{HB}$ at $20^{\circ} \mathrm{C}$. Spectra are shown before addition (curve 1), and curves 2-8 were obtained after $2 \mathrm{~min}, 10 \mathrm{~min}, 30 \mathrm{~min}, 60 \mathrm{~min}, 210 \mathrm{~min}, 1 \mathrm{day}$, and 3 days of reaction.

neously monitored. (Correction was made for the slow spontaneous destruction of $\mathrm{NADH}$ at this $\mathrm{pH}$ and temperature.) From these data, a partition ratio equivalent to the average number of turnovers occurring before inactivation can be calculated at any time during the inactivation. When this ratio was determined at progressively longer times, it increased from a value of 3.2 turnovers/inactivation after a third of the enzyme had inactivated to 9.4 turnovers/inactivation after complete inactivation. When corrected, however, for the $15-20 \%$ of this enzyme preparation exhibiting a much lower specific activity, ${ }^{2}$ a constant ratio of about 5 turnovers/inactivation (independent of $\alpha \mathrm{HB}$ concentration) was found for the major portion $(80 \%)$ of the inactivation. ${ }^{3}$

The partition ratio found with this enzyme should be contrasted with three other $\alpha$-hydroxy acid oxidizing flavoenzymes which are irreversibly inactivated by $\alpha \mathrm{HB}: M$. smegmatis L-lactate oxidase was found to undergo 110 turnovers/inactivation (Ghisla et al., 1976); the Escherichia coli D-lactate dehydrogenase, 15-30 turnovers/inactivation (Walsh et al., 1972); and the rat kidney $L-\alpha$-hydroxy acid oxidase, 25 turnovers/inactivation (Cromartie \& Walsh, 1975). Thus, substantially fewer turnovers take place before inactivation with this enzyme.

Formation of a Pink Chromophore on Reaction with $\alpha H B$. $\alpha \mathrm{HB}$ causes dramatic spectral changes when mixed with the enzyme under anaerobic conditions (Figure 3 ). The absorption peaks of the oxidized flavin at 386 and $454 \mathrm{~nm}$

${ }^{2}$ Anaerobic inactivation experiments monitored spectrally revealed that the final $20 \%$ activity loss corresponded to about $30 \%$ of the enzyme flavin. This was not surprising, since isolated D-lactate dehydrogenase exhibits variable activity to flavin ratios (AFR) ranging from 107 to 140 (Olson \& Massey, 1979). The observed inhomogeneity in this preparation (AFR 115) can be accounted for by an estimated 15-20\% of a much less active disulfide form of the enzyme as postulated in the preceding manuscript (Olson \& Massey, 1979).

3 Thus, the partition ratio of 9.4 found after complete inactivation indicates that the small fraction of enzyme of lower specific activity is inactivated with a higher partition ratio. 
gradually decrease with concomitant formation of new absorption bands at 522,390 , and $330 \mathrm{~nm}$. These changes in the absorption spectrum of the flavin are visible to the eye as a change in the characteristic yellow color of the flavin to pink. After an initial spectral perturbation upon adding $\alpha \mathrm{HB}$, approximate isosbestic points occur at 502 and $337 \mathrm{~nm}$. These isosbestics are held until maximal bleaching occurs in the 350-500-nm region. This required about $4 \mathrm{~h}$ in the experiment of Figure 3. Subsequently, a very slow continued increase in the 522-nm band takes place over the course of several days with little absorbance change between 350 and $450 \mathrm{~nm}$. These latter absorption changes are characterized by a new set of isosbestic points at 460,415 , and $350 \mathrm{~nm}$.

A modification of the flavin chromophore is also evident when the reaction is monitored by fluorescence. The oxidized flavin fluorescence is observed to decay with time while a new emission peak appears at $585 \mathrm{~nm}$ (excitation wavelength 530 $\mathrm{nm})$.

When air was admitted to the reaction mixture after 3 days at room temperature in the experiment of Figure 3, increased absorption appeared between 350 and $500 \mathrm{~nm}$. The calculated difference spectrum coincided with oxidized minus reduced native enzyme. When air was admitted at earlier times in similar inactivation experiments, increased absorption was always found having the same type of difference spectrum. Such experiments showed that the isosbestic bleaching induced by $\alpha \mathrm{HB}$ is due to both flavin reduction and pink chromophore formation occurring at the same time. This is consistent with the dual role of $\alpha \mathrm{HB}$ as both a substrate and inactivator. In contrast to the pink chromophore, however, reduced enzyme accumulated up to the point at which maximal bleaching in the 350-500-nm region had occurred. The subsequent slow increases in the pink chromophore were found to be accompanied by a depletion in the amount of reduced enzyme. Thus, it appeared that pink flavin was arising from reduced enzyme in this stage of the reaction. Further evidence supporting this conclusion is given later.

Figure 2 shows that formation of the pink chromophore parallels the inactivation of the enzyme when both are simultaneously monitored in an anaerobic experiment. This is consistent with the enzyme inactivation being due to the chemical modification of the flavin. The rate of formation of the pink flavin in the first phase of the reaction was highly dependent on the concentration of $\alpha \mathrm{HB}$ used and exhibited saturation kinetics. The maximal rate ${ }^{4}$ extrapolated to infinite $\alpha \mathrm{HB}$ was $0.5 \mathrm{~min}^{-1}$.

Using resolved D- and L- $\alpha \mathrm{HB}$, we demonstrated that the pink adduct was formed by only the $\mathrm{D}$ isomer. Furthermore, the $\mathrm{L}$ isomer did not inhibit the rate of reaction of the $\mathrm{D}$ isomer. These observations are consistent with the demonstrated specificity of the enzyme for D-lactate and the failure to find competitive inhibition by L-lactate (Olson \& Massey, 1979).

Purification of the Pink Flavin. After reaction with $\alpha \mathrm{HB}$, the modified flavin of $D$-lactate dehydrogenase could be released by precipitating the protein with $5 \%(\mathrm{w} / \mathrm{v}) \mathrm{Cl}_{3} \mathrm{AcOH}$. After neutralization, the spectrum of the released flavin resembled that of the bound flavin except for a lowered extinction (Figure 4).

Thin-layer chromatography (in $6 \% \mathrm{Na}_{2} \mathrm{HPO}_{4} \cdot 12 \mathrm{H}_{2} \mathrm{O}$ on silica gel plates) of the released flavin revealed four reddish

\footnotetext{
${ }^{4}$ Log plots of the absorbance changes at 540 or $450 \mathrm{~nm}$ gave several phases. This kinetic complexity has also been observed when reduction of the enzyme by D-lactate was monitored by the stopped-flow apparatus. The quoted maximal inactivation rate was obtained by extrapolation of the fastest phase.
}

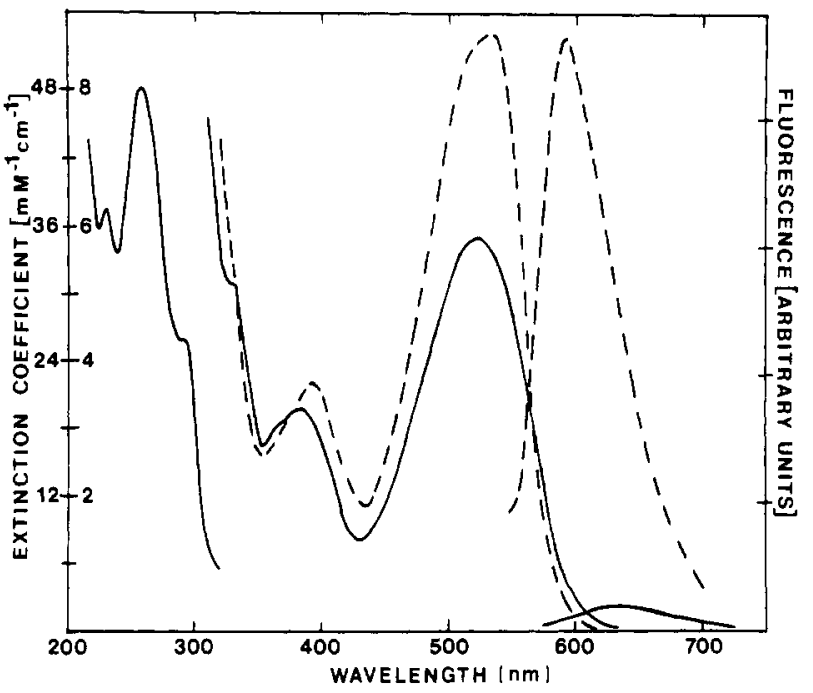

FIGURE 4: Binding of pink FAD to apo-D-amino acid oxidase. Pink FAD $\left(A_{522}=0.085\right)$ in $0.1 \mathrm{M}$ sodium pyrophosphate, $\mathrm{pH} 8.5$, at 20 ${ }^{\circ} \mathrm{C}$, was titrated with increments of a stock apo-DAAO solution (3.16 $\times 10^{-4} \mathrm{M}$ in the same buffer) until fluorescence and absorption changes were complete. (-) shows the fluorescence emission (excitation 525 $\mathrm{nm}$ ) and absorption spectrum of the purified pink FAD, and (..-) shows the fluorescence emission (excitation at $535 \mathrm{~nm}$ ) and absorption spectrum of the fully formed pink FAD-DAAO complex.

fluorescent spots not present in untreated enzyme, ${ }^{5}$ but only one of these fluorescent spots (incompletely separated from unreacted FAD) had any significant pink color. It was found that pink flavin can be purified free of unreacted FAD by passage through a Sephadex G-25 superfine column. When the fractions from this column were monitored by fluorescence, highly fluorescent fractions with little pink color preceded and overlapped the major pink fractions, followed by FAD. Complete removal of contaminating highly fluorescent flavins ${ }^{5}$ was achieved by preparative TLC in the solvent described above. The spectrum of the major pink component is shown in Figure 4.

Spectral Characteristics of Pink Flavin. In the absorption spectrum of the major component produced from FAD (Figure 4), peaks occur at 522, 382, 330 (sh), 291 (sh), 257, and 229 $\mathrm{nm}$. The large red shift in the long-wavelength visible maximum suggests that extended conjugation of the flavin chromophore has occurred. The fluorescence emission spectrum shows a maximum at $635 \mathrm{~nm}$ and an intensity $2.8 \%$ that of FAD on a molar basis at $20^{\circ} \mathrm{C} .{ }^{6}$

The purified major pink flavin shows only one emission peak whose maximum is constant when the excitation wavelength

\footnotetext{
${ }^{5}$ Of the three minor components showing reddish fluorescence, one was shown to be a small amount of the major pink component that had hydrolyzed to the FMN level (see next section). The remaining two pink flavin spots represent two new highly fluorescent flavins arising from reaction of $\alpha \mathrm{HB}$ with modified flavins present in the isolated enzyme. This conclusion was reached from the following evidence. First, apoenzyme reconstituted with authentic FAD and reacted with $\alpha \mathrm{HB}$ yields only the major pink flavin with low fluorescence. When the apoenzyme is reconstituted with flavin released from native enzyme and then reacted with $\alpha \mathrm{HB}$, the highly fluorescent pink flavins are found to comprise the majority of the observed fluorescence. Second, variable yields of highly fluorescent pink flavins are obtained from different enzyme preparations. The two minor forms were estimated to make up at most $10 \%$ of the total pink flavin on a molar basis, but one was 34 times more fluorescent and the other 9 times more fluorescent than the major component (assuming similar extinctions).

${ }^{6}$ The fluorescence with $585-\mathrm{nm}$ emission maximum observed in monitoring the reaction of $\alpha \mathrm{HB}$ with the enzyme is due largely to the minor pink flavin component, which is much more intensely fluorescent than the major component.
} 
is varied over a wide range, and its excitation spectrum matches the absorption spectrum, indicating that the major pink species is free from any contaminating fluorescent flavins.

Binding of the Pink Flavin to Apo-D-amino Acid Oxidase. The purified compound was shown to be a FAD analogue by its ability to bind to apo-D-amino acid oxidase (apo-DAAO), which binds only FAD and analogues of FAD, but not FMN (McCormick et al., 1964). Figure 4 shows the dramatic fluorescence and absorption spectral changes that occur upon addition of apo-DAAO to the pink flavin. The fluorescence maximum intensity increases 25 -fold with a blue shift in the emission maximum to $593 \mathrm{~nm}$, and the excitation spectrum now shows peaks at 535 and $395 \mathrm{~nm}$. This is in contrast to the binding of FAD to the same apoprotein, where fluorescence is quenched. In the absorption spectrum, the maximum absorption increases 1.5 -fold, the peaks undergoing red shifts to 534 and $392 \mathrm{~nm}$ with a resolution of the $534-\mathrm{nm}$ band to give a shoulder at $510 \mathrm{~nm}$. In addition, the $330-\mathrm{nm}$ shoulder is much less resolved.

The large fluorescence enhancement upon binding to apo-DAAO provides one method for determining the extinction coefficient of the pink flavin. Apoprotein with a known concentration of flavin binding sites (see Materials and Methods) is added to a sample of the pink compound in small aliquots until no further fluorescence changes are observed. From the stoichiometric end point, the pink flavin concentration is determined. The binding of the pink flavin to the apoprotein turned out to be too weak to get the end point by extrapolating a tangent from the initial portion of the curve to the final fluorescence, so a least-squares fitting routine was done to a theoretical binding curve derived from the equation (Shoemaker \& Garland, 1962)

$$
\text { apo-DAAO + pink flavin } \rightleftharpoons \text { apo-DAAO-pink flavin }
$$

Benzoate was found not to bind to the apoenzyme-pink flavin complex. This contrasts with its tight binding to the native enzyme, which increases the effective binding strength of the flavin (Massey et al., 1966). An average of several experiments gave a $K_{\mathrm{d}}$ of $7.1 \times 10^{-7} \mathrm{M}$ and a value of $5910 \mathrm{M}^{-1} \mathrm{~cm}^{-1}$ for the extinction coefficient.

The extinction coefficient was also determined directly in experiments such as shown in Figure 3 by equating the amount of enzyme flavin reacted (determined by subtracting the amount of oxidized flavin returning upon admission of air in an anaerobic experiment from the initial enzyme flavin concentration) with the amount of pink flavin formed. In three experiments at $\mathrm{pH} 7.0$, an average value of $6230 \mathrm{M}^{-1} \mathrm{~cm}^{-1}$ was obtained. However, upon release from protein, the absorbance drops and the extinction coefficient of the free pink flavin was calculated to be $5760 \mathrm{M}^{-1} \mathrm{~cm}^{-1}$, in good agreement with the value obtained by titration.

Conversion to an FMN Analogue and Binding to Apoflavodoxin. If the pink flavin is an FAD analogue, then snake venom phosphodiesterase should hydrolyze the pyrophosphate anhydride bond and release AMP, giving an FMN analogue. Phosphodiesterase treatment does convert the pink flavin quantitatively to a new species whose migration on TLC is in the direction expected for loss of AMP from the molecule [see Table I of Ghisla et al. (1979)]. Absorption and fluorescence changes are also observed upon adding the phosphodiesterase. Figure 5 shows the absorption spectrum of the pink FMN (the UV spectrum was determined after removal of the snake venom protein and released AMP by passage over an apoflavodoxin column as detailed under Materials and Methods). An increase in extinction is observed over the visible range. The intensity of the $522-\mathrm{nm}$ band increases 1.07 times, the

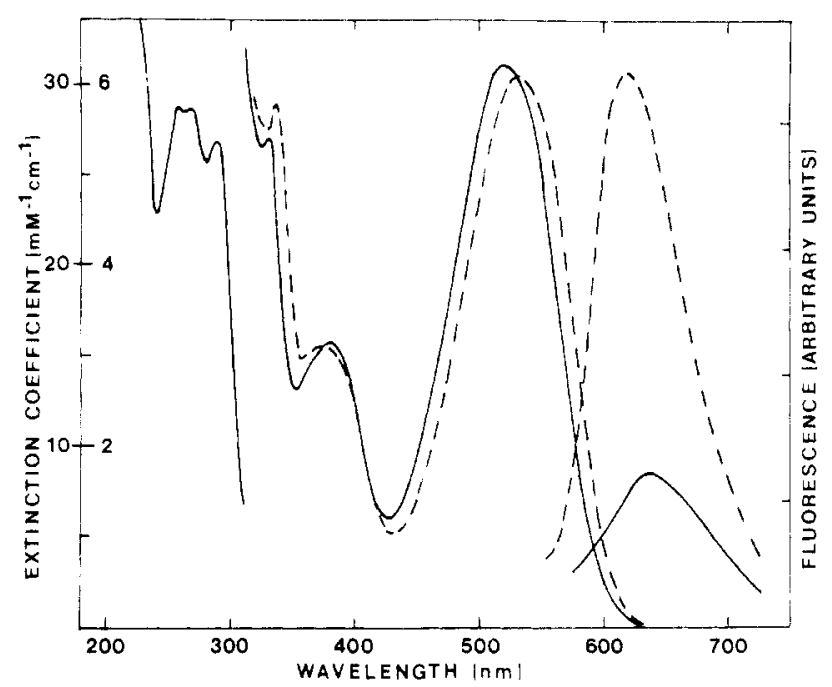

FIGURE 5: Binding of pink FMN to apoflavodoxin. Pink FMN $\left(A_{521}\right.$ $=0.084)$ in $0.1 \mathrm{M} \mathrm{KP}, \mathrm{pH} 7.0$, at $20^{\circ} \mathrm{C}$, was titrated with increments of a stock apoflavodoxin solution $\left(1.56 \times 10^{-4} \mathrm{M}\right.$ in the same buffer) until fluorescence and absorption changes were complete. $(-)$ shows the fluorescence emission (excitation $520 \mathrm{~nm}$ ) and absorption spectrum of the purified pink FMN, and (...) shows the fluorescence emission (excitation $530 \mathrm{~nm}$ ) and absorption spectrum of the fully formed pink FMN-flavodoxin complex.

absorption maximum undergoing small blue shifts to 521 and $380 \mathrm{~nm}$ and the $330-\mathrm{nm}$ shoulder becoming better resolved. The UV region changes more dramatically with a significant decrease in absorption of the $257-\mathrm{nm}$ band consistent with loss of the nucleotide absorption of AMP and appearance of a new peak at $268 \mathrm{~nm}$. Surprisingly, the fluorescence decreases to $52 \%$ of the initial intensity with an emission maximum of 635 $\mathrm{nm}$. This again is in contrast to FAD which undergoes an 11-fold increase in fluorescence upon conversion to FMN (Bessey et al., 1949).

Pink FMN binds to the FMN-specific apoflavodoxin from $M$. elsdenii, confirming that conversion to an FMN analogue has taken place. Significant absorption and fluorescence spectral changes again are observed, reflecting the binding to flavodoxin (Figure 5). The longer wavelength maximum red shifts to $530 \mathrm{~nm}$ and the $330-\mathrm{nm}$ shoulder becomes a peak at $337 \mathrm{~nm}$, while the $380-\mathrm{nm}$ band with its slight shoulder at about $370 \mathrm{~nm}$ becomes less resolved and is now centered at about $370 \mathrm{~nm}$. The fluorescence changes show a 3.6-fold enhancement in the maximum intensity, the emission maximum shifting to $620 \mathrm{~nm}$. This contrasts dramatically with FMN whose fluorescence is quenched to less than $1 \%$ of its initial value upon binding to $M$. elsdenii apoflavodoxin (Mayhew, 1971). A $K_{\mathrm{d}}$ of $4.5 \times 10^{-7} \mathrm{M}$ and an average extinction from several experiments of $6190 \mathrm{M}^{-1} \mathrm{~cm}^{-1}$ were determined for pink FMN by titration with apoflavodoxin. This latter value compares favorably with the value $6240 \mathrm{M}^{-1}$ $\mathrm{cm}^{-1}$ obtained from the extinction increase upon conversion of pink FAD to pink FMN.

Possible Mechanisms of Inactivation. The evidence presented has shown that D-lactate dehydrogenase turns over $\alpha \mathrm{HB}$ on an average of 5 times before being irreversibly inactivated. The inactivation is accompanied by the parallel conversion of the enzyme flavin to a stable pink flavin adduct. The structure of the adduct as determined in the following paper (Ghisla et al., 1979) indicates a stoichiometric reaction to have taken place between enzyme flavin and suicide inhibitor as expected for an active site-directed reaction.

A mechanism for this suicide inactivation must involve the conversion of $\alpha \mathrm{HB}$ to a reactive form by some step in the 
Scheme II

$$
\mathrm{HC} \equiv \mathrm{C}-\underset{\mathrm{OH}}{\ominus}-\mathrm{COO}^{\ominus} \longrightarrow \mathrm{H} \stackrel{\ominus}{\mathrm{C}}=\mathrm{C}=\underset{\mathrm{OH}}{\mathrm{C}}-\mathrm{COO}^{\ominus}
$$

Scheme III

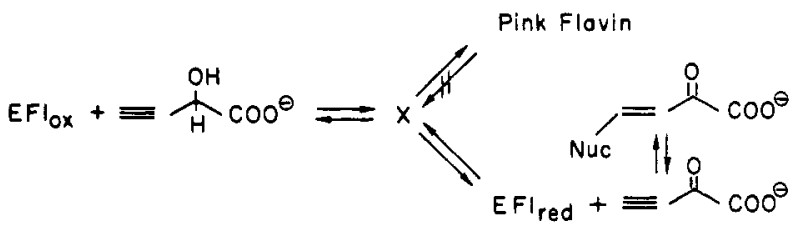

normal catalytic mechanism of the enzyme. Previous work on similar flavoenzymes inactivated by $\alpha \mathrm{HB}$ has suggested two likely candidates. First, abstraction of the $\alpha$-hydrogen of the substrate to form a carbanion is believed to be the initiating step in substrate dehydrogenation by several flavin enzymes (Bright \& Porter, 1975; Walsh, 1978). The carbanion formed from $\alpha \mathrm{HB}$, however, is equivalent to an allene carbanion, which is expected to be highly reactive as a nucleophile (Scheme II). Second, oxidation of $\alpha \mathrm{HB}$ yields $\alpha \mathrm{KB}$, a molecule which could undergo Michael-type addition reactions with nucleophiles such as the reduced flavin to form the modified coenzyme. Such reactions of $\alpha \mathrm{KB}$ have been reported (Kaczorowski et al., 1975). These two mechanistic alternatives are diagrammed in Scheme III. The further experiments described were therefore designed to distinguish between these two possible inactivation paths.

Reaction of Reduced Enzyme with $\alpha K B$. One approach to testing the Michael-reaction path was to study the reaction from the reverse direction. If $\alpha \mathrm{KB}$ is indeed the reactive precursor of the pink flavin, then one might expect the rate of pink adduct formation to be faster from reduced enzyme and $\alpha \mathrm{KB}$ than from oxidized enzyme and $\alpha \mathrm{HB}$ since possible rate-determining steps in the forward direction (e.g., proton abstraction, electron transfer, etc.) are bypassed (cf. Scheme III).

The production of the pink flavin from oxidized enzyme and $\alpha \mathrm{HB}$ has been described (Figure 3 ) as a two-stage reaction. In the first stage oxidized flavin is converted to both pink flavin and reduced enzyme. In a second stage, which requires several days, further pink flavin is formed and appears to arise from reduced enzyme. One might be tempted to conclude from this initial result that the production of pink flavin from reduced enzyme and $\alpha \mathrm{KB}$ is much too slow to proceed by the $\mathrm{Mi}$ chael-reaction mechanism. However, several further experiments demonstrated that the accumulation of reduced enzyme by the end of the first stage was actually due to the trapping of $\alpha \mathrm{KB}$ by Michael-type reactions with solution nucleophiles and that the subsequent slow formation of pink flavin from reduced enzyme occurred because these trapping reactions were reversible.

Thus, the Michael reaction of $\alpha \mathrm{KB}$ with protein residues of D-lactate dehydrogenase could be directly observed when inactivations were carried out aerobically, conditions under which $\alpha \mathrm{KB}$ could accumulate. This was evident from the extensive development of a near-UV absorption similar to that reported by Marcotte \& Walsh $(1976,1978)^{7}$ for the al-

\footnotetext{
${ }^{7}$ Marcotte \& Walsh $(1976,1978 \mathrm{a}, \mathrm{b})$ demonstrated that the alkylation of D-amino acid oxidase by propargylglycine (2-amino-4-pentynoate) involved the rearrangement of the oxidation product (2-imino-4-pentynoate) to an electrophilic allene which randomly alkylated nucleophilic protein residues to produce a short wavelength absorbing chromophore with $\epsilon_{317}$ $=15000 \mathrm{M}^{-1} \mathrm{~cm}^{-1}$. The alkylation of D-lactate dehydrogenase by $\alpha \mathrm{KB}$ would be expected to produce a similar chromophore.
}

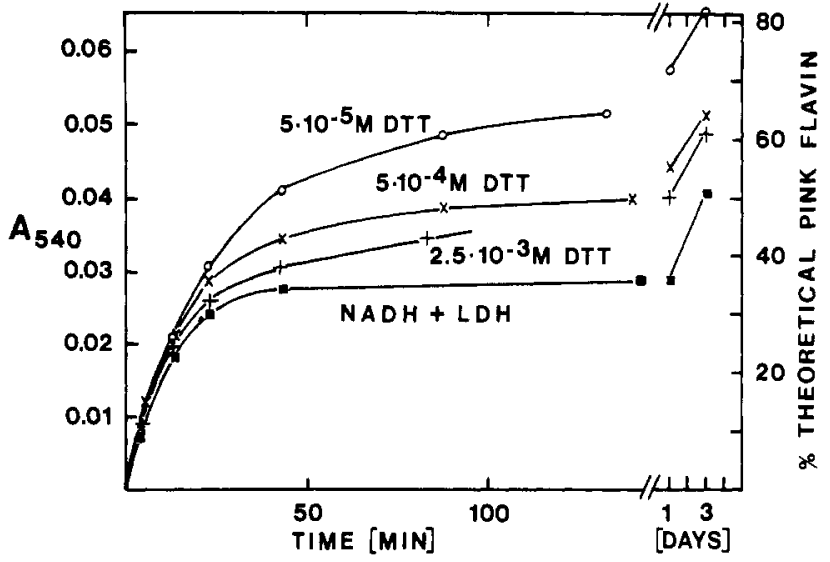

FIGURE 6: Effect of DTT or rabbit LDH plus NADH on the course of pink flavin production in the anaerobic reaction of D-lactate dehydrogenase with $\alpha \mathrm{HB}$. Enzyme $(13.4 \mu \mathrm{M})$ in $0.1 \mathrm{M} \mathrm{KP}{ }_{\mathrm{j}}, \mathrm{pH} 7.0$, was reacted anaerobically with $420 \mu \mathrm{M}$ DL- $\alpha \mathrm{HB}$ at $20^{\circ} \mathrm{C}$ in the presence of either $5 \times 10^{-5} \mathrm{M}$ DTT $(0), 5 \times 10^{-4} \mathrm{M}$ DTT $(x), 2.5$ $\times 10^{-3} \mathrm{M}(\mathrm{DTT})(+)$, or $83 \mu \mathrm{g} / \mathrm{mL}$ rabbit muscle LDH plus $110 \mu \mathrm{M}$ NADH (D). The reaction was monitored by periodically scanning the spectrum. The amount of pink flavin formed with time is presented either as the absorbance at $540 \mathrm{~nm}$ or the percent theoretical pink flavin, $100 \%$ representing complete reaction of enzyme flavin (calculated from the extinction coefficient presented in the text).

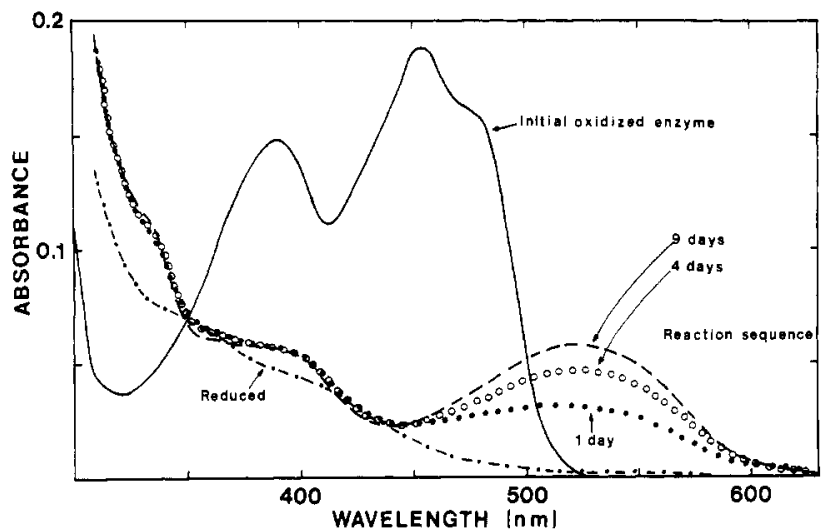

FIGURE 7: Formation of pink flavin from reduced enzyme and the putative Michael reaction product of DTT with $\alpha \mathrm{KB}$. To $14.7 \mu \mathrm{M}$ oxidized enzyme containing $20 \mathrm{mM}$ sodium oxalate in $0.1 \mathrm{M} \mathrm{KP}$, pH 7.0, plus $100 \mu \mathrm{M}$ DTT was added anaerobically $1 \mu \mathrm{M}$ 5-deazariboflavin. The solution was irradiated for $2 \mathrm{~min}$ to give reduced enzyme $(-\cdots)$. The putative Michael reaction product of DTT with $\alpha \mathrm{KB}$ (concentrated to a small volume) was then mixed in, and the reaction was allowed to proceed at room temperature. Spectra are shown after $1(\cdots), 4(0)$, and 9 days $(\cdots)$ of reaction.

kylation of D-amino acid oxidase by propargylglycine. The short wavelength absorption was shown to be associated with the protein by resolution of the flavin by Sephadex G- 25 gel filtration. To further confirm alkylation of the protein, we carried out the aerobic inactivation in the presence of a good nucleophile such as DTT (at 1-2 mM), reported to be a good scavenger of $\alpha \mathrm{KB}$ (Kaczorowski et al., 1975; Cromartie \& Walsh, 1975). As expected, the short wavelength absorption did not appear. The inclusion of rabbit muscle $\mathrm{LDH}$ and NADH which would rapidly convert $\alpha \mathrm{KB}$ to $\mathrm{L}-\alpha \mathrm{HB}$ (Scheme I) also prevented accumulation of such short wavelength absorption.

The trapping of $\alpha \mathrm{KB}$ in anaerobic inactivations was demonstrated by running the reaction in the presence of varying concentrations of trapping agent. Figure 6 shows that, as predicted, the amount of pink flavin produced in the first stage of the reaction decreases from 72 to $50 \%$ when the concentration of DTT is increased from $5 \times 10^{-5}$ to $2.5 \times 10^{-3}$ 
M. When rabbit muscle LDH and NADH are used, the least amount (36\%) of pink flavin is formed in stage one. In this latter experiment the amount of reduced enzyme accumulated was stoichiometric with the NADH oxidized.

Since some DTT was always present in the enzyme, ${ }^{8}$ the two-stage reaction was always observed. However, higher concentrations of $\alpha \mathrm{HB}$ were found to favor pink flavin formation in the first stage. A total of $70,74,80$, and $90 \%$ of the enzyme flavin was converted to pink flavin by the end of the first stage of the reaction when $0.23,0.45,1.14$, and 2.49 $\mathrm{mM}$, respectively, D $\alpha \mathrm{HB}$ was used (at $0.1 \mathrm{mM}$ DTT).

The reversibility of the Michael reaction of $\alpha \mathrm{KB}$ with DTT was demonstrated in the experiment shown in Figure 7. The Michael addition product of $\alpha \mathrm{KB}$ with DTT was generated by incubating D-lactate dehydrogenase aerobically with $\alpha \mathrm{HB}$ in the presence of $2 \mathrm{mM}$ DTT. After complete inactivation, the reaction mixture was passed through a Sephadex G-25 column, and the small molecular weight fraction was isolated. This was then mixed anaerobically with enzyme which had been photochemically reduced with oxalate and catalytic deazaflavin (Olson \& Massey, 1979). Very slow formation of pink flavin characteristic of the second phase of the anaerobic inactivation took place.

The above results demonstrated that $\alpha \mathrm{KB}$ is a reactive molecule, making the Michael mechanism for pink flavin formation an attractive possibility. It was also clear from the above results, however, that the rate of formation of the pink adduct from reduced enzyme and $\alpha \mathrm{KB}$ needed to be determined in a more direct manner. Since $\alpha \mathrm{KB}$ is unstable in solution, this required its in situ generation from $L-\alpha \mathrm{HB}$ by using rabbit LDH and oxidized pyridine nucleotide.

$\mathrm{ApAD}^{+}$was chosen because of its more favorable redox potential, and resolved $\mathrm{L}-\alpha \mathrm{HB}$ was used to minimize reaction of the $D$ isomer with oxidized enzyme. The experiment was done as follows. Enzyme was photochemically reduced with oxalate and catalytic deazaflavin (Olson \& Massey, 1979). $\mathrm{ApAD}^{+}$and $\mathrm{L}-\alpha \mathrm{HB}$ were then tripped in succession from separate side arms into the main cell compartment containing the rabbit muscle LDH. It was calculated that a 1.6-fold excess of $\alpha \mathrm{KB}$ over enzyme would be generated. Virtually complete reoxidation occurred immediately after mixing with L- $\alpha$ HB. Negligible reoxidation occurred after $\mathrm{ApAD}^{+}$was mixed, making it unlikely that oxidation was due to residual oxygen. Furthermore, from the $E_{0}^{\prime}$ of $-122 \mathrm{mV}$ determined for the $\alpha \mathrm{HB} / \alpha \mathrm{KB}$ couple by using rabbit LDH and $\mathrm{NAD}^{+}$ and the estimated potential of the flavin $\left(-219 \mathrm{mV}\right.$ at $\left.20^{\circ} \mathrm{C}\right)$ (Olson \& Massey, 1979), the large separation in potentials predicts that complete reoxidation should occur at equilibrium. Following the rapid reoxidation in this experiment, pink flavin arose slowly at a rate expected for the amount of contaminating $\mathrm{D}-\alpha \mathrm{HB}$ present. This experiment thus showed that $\alpha \mathrm{KB}$ reacts with reduced enzyme to yield oxidized enzyme much more rapidly than pink flavin.

In an attempt to overcome the problems of enzyme reoxidation, another experiment was performed in which an excess of D-lactate was used to reduce the enzyme. The potential of the system was thus poised so that enzyme was maintained in the reduced state. When the $\alpha \mathrm{KB}$-generating system used in the previous experiment was anaerobically mixed, again, no rapid formation of pink flavin occurred as might be ex-

\footnotetext{
${ }^{8}$ Comparison could not be made with experiments done with no DTT present since this caused substantial losses in enzyme activity with corresponding incomplete reaction of the enzyme flavin. It is likely, however, that reaction of $\alpha \mathrm{KB}$ with the protein or water may be contributing to some of the trapping.
}

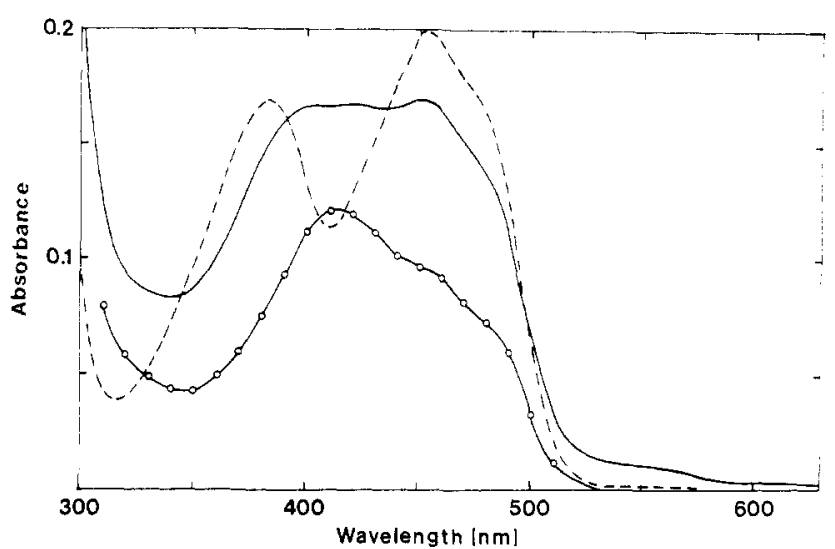

FIGLIRE 8: Conversion of the native flavin of D-lactate dehydrogenase to two different modified flavins by $\alpha \mathrm{HB}$ in the presence of air. Enzyme $(15.4 \mu \mathrm{M})$ was reacted with $450 \mu \mathrm{M}$ DL- $\alpha \mathrm{HB}$ in $0.1 \mathrm{M}$ borate buffer containing $0.1 \mathrm{M} \mathrm{KCl}, \mathrm{pH} 8.5$, at $20^{\circ} \mathrm{C}$. (...) is the initial spectrum before addition of $\alpha \mathrm{HB}$, and $(-)$ is the spectrum obtained after $13 \mathrm{~min}$ of reaction. $(0)$ represents a calculated spectrum obtained by subtracting $11 \%$ pink flavin and $35 \%$ native flavin from the latter spectrum.

pected if the reaction were indeed occurring from a reduced enzyme- $\alpha \mathrm{KB}$ complex. A total of $47 \%$ pink flavin was formed at a rate even slower than that of the previous experiment.

Reaction with Vinylglycollate. In order to assess the possibility of flavin modification occurring from $\alpha \mathrm{KB}$ and reduced flavin by a Michael-type reaction, we incubated the enzyme with $\alpha$-hydroxybutenoate (vinylglycollate). This compound, when oxidized by D-lactate dehydrogenase, would yield $\alpha$-ketobutenoate which would be expected to be as good a Michael acceptor as $\alpha \mathrm{KB}$ (Walsh, 1977, 1978). When the experiment was done anaerobically with an excess of vinylglycollate, only reduction of the flavin coenzyme was observed to occur. Even under aerobic conditions where several turnovers were allowed to occur, no evidence of flavin modification was seen. The enzyme is, however, inactivated during aerobic turnover, presumably by random alkylation of protein nucleophiles by the $\alpha$-ketobutenoate produced, similar to what was observed with $\alpha \mathrm{KB}$. As expected, protection is rendered by agents that can trap the $\alpha$-ketobutenoate produced

Trapping of an Intermediate on the Reaction Pathway by Oxygen. While the above experiments seem to argue against a Michael mechanism, no direct evidence exists for the carbanion mechanism. One line of investigation which provided further evidence relevant to the mechanism came from a study of the aerobic inactivation. When D-lactate dehydrogenase is inactivated by $\alpha \mathrm{HB}$ aerobically, considerably less pink flavin was produced even in the presence of an $\alpha \mathrm{KB}$ trap to prevent protein alkylation (Figure 1). In one typical anaerobic experiment, a $70 \%$ yield of pink flavin (with $30 \%$ reduced enzyme) was obtained in 1 day whereas only a $45 \%$ yield of pink adduct was obtained aerobically over this same time. This difference could not be attributed to exhaustion of $\alpha \mathrm{HB}$ by turnover, for addition of a second equal aliquot of enzyme caused the amount of pink chromophore to approximately double. That some other flavin modification might be occurring was suggested by the appearance of small increases in absorption in the $400-420-\mathrm{nm}$ trough of the oxidized flavin absorption. This was much more evident when the inactivation was done at $\mathrm{pH} 8.5$ where only $11 \%$ of the enzyme flavin was converted to pink flavin. The amount of absorption appearing in the 400-420-nm region was now much greater than that found at $\mathrm{pH} 7.0$, and two new peaks were discernible in this region occurring at about 400 and $420 \mathrm{~nm}$ 


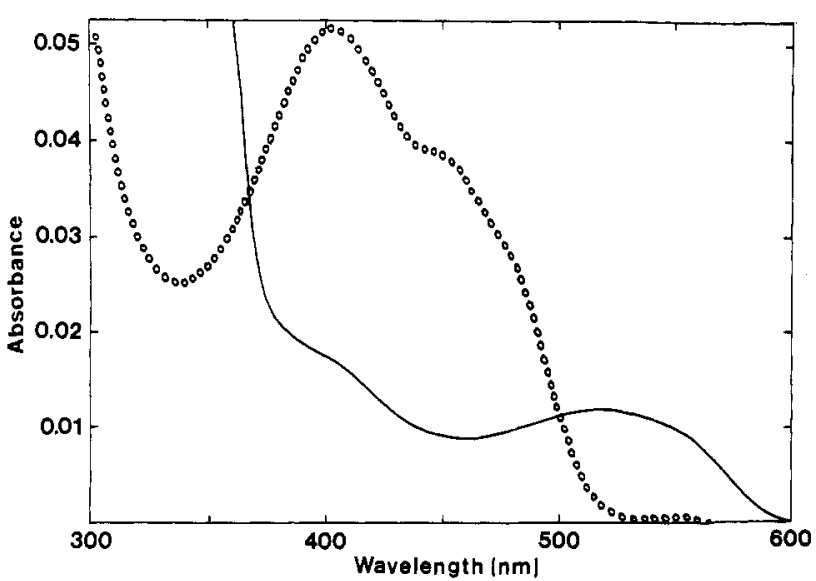

FIGURE 9: Conversion of the purified yellow $\alpha \mathrm{HB}$-modified flavin to pink flavin. The purified yellow $\alpha$ HB-modified flavin in water $(0)$ was made anaerobic and then mixed with a few grains of dithionite. $(-)$ is the spectrum obtained immediately after mixing. Dithionite absorption contributes to the spectrum below $500 \mathrm{~nm}$.

(Figure 8). That a different flavin species was formed was also evident from changes in the flavin fluorescence. At pH $8.5,65 \%$ of the flavin fluorescence was lost, but only $11 \%$ could be accounted for by reaction to form the pink flavin. (Enzyme instability at this $\mathrm{pH}$ contributed to less of the flavin reacting than at lower $\mathrm{pH}$ values.) Subtracting $11 \%$ pink flavin and $35 \%$ native flavin from the spectrum of the reaction mixture gave a calculated spectrum with a peak at $412 \mathrm{~nm}$, a shoulder at $460 \mathrm{~nm}$, and a trough at $340-350 \mathrm{~nm}$ (Figure 8).

When the flavin was released in such an experiment and analyzed by thin-layer chromatography, an additional yellow spot with yellow fluorescence was found. The absorption spectrum of this new component was found to be very similar to the calculated spectrum (Figure 9).

From a consideration of the possible chemical mechanisms for formation of the pink flavin [see Ghisla et al. (1979)], it appeared that this new component might have arisen from an intermediate on the path to pink flavin which was trapped by reaction with molecular oxygen. If this were so, reduction of this unusual flavin by a chemical reductant such as dithionite should regenerate the original intermediate which should then convert to pink flavin. The results of this experiment appear in Figure 9 where it can be seen that pink flavin did indeed arise upon reduction of the intermediate. Maximal pink flavin formation was complete by the time the spectrum was recorded. The relevance of this intermediate to the two possible inactivation mechanisms is discussed more thoroughly in the following paper (Ghisla et al., 1979) in terms of chemical structure. It should suffice to say, however, at this point that this intermediate from chemical considerations is most likely to have arisen from the carbanion inactivation pathway, lending further support to a carbanion mechanism for this enzyme.

\section{Discussion}

The results presented in this paper show that $\mathrm{D}-\alpha \mathrm{HB}$ acts as both a substrate and an irreversible inactivator of D-lactate dehydrogenase, inactivation resulting from irreversible chemical modification of the flavin coenzyme. The partitioning of $\alpha \mathrm{HB}$ between normal substrate oxidation and irreversible inactivation is a property characteristic of all suicide reactions which have been studied (Walsh, 1977, 1978). It indicates that, during turnover, the suicide substrate is converted to a highly reactive species by some step in the catalytic mechanism of the enzyme. The reactive intermediate inactivates the enzyme by reacting either with an essential protein residue or with the coenzyme as in the case of many flavoproteins. The partition ratio with D-lactate dehydrogenase of $\sim 5$ turnovers/inactivation provides an example of the most efficient inactivation yet reported for $\alpha$-hydroxy acid oxidizing flavin enzymes inactivated by $\alpha \mathrm{HB}$.

As with all other acetylenic suicide inactivators of flavin enzymes which have been studied, two intermediates expected to occur on the catalytic path of $\alpha \mathrm{HB}$ oxidation by D-lactate dehydrogenase qualify as potentially reactive species. An allene carbanion of $\alpha \mathrm{HB}$ would be generated if the enzyme utilized a carbanion mechanism (Scheme II). On the other hand, the oxidation of $\alpha \mathrm{HB}$ yields $\alpha \mathrm{KB}$, a molecule demonstrated to be reactive toward nucleophiles (Kaczorowski et al., 1975). The alkylation of D-lactate dehydrogenase by $\alpha$ KB provides yet another example of this reactivity.

The inactivation of L-lactate oxidase by $\alpha \mathrm{HB}$ presented the same mechanistic alternatives. A kinetic study of the suicide reaction showed that adduct formation proceeded by an initial rapid reduction of the flavin $\left(62 \mathrm{~s}^{-1}\right)$ to form a reduced enzyme-keto acid complex which subsequently converted to the irreversible $\mathrm{N}(5)-\mathrm{C}(4 \mathrm{a})$ cyclic adduct much more slowly (1 $\mathrm{s}^{-1}$ ) (Ghisla et al., 1976) (Scheme III). Thus, reduction of the enzyme preceded formation of the covalent adduct. However, it could not be concluded from this result that inactivation occurred via a Michael addition of reduced flavin to $\alpha \mathrm{KB}$. This is because the reduced enzyme- $\alpha \mathrm{KB}$ complex might exist in rapid equilibrium with an oxidized enzyme- $\alpha \mathrm{HB}$ carbanion pair and the latter might be the actual precursor of the flavin adduct (cf. Scheme III). In this case, the adduct would only appear to arise from the thermodynamically favored reduced enzyme- $\alpha \mathrm{KB}$ complex.

The reaction of D-lactate dehydrogenase with $\alpha \mathrm{HB}$ is expected to follow the same reaction scheme but with sizable differences in the individual rate constants. First of all, the rate of adduct formation is much lower $\left(0.5 \mathrm{~min}^{-1}\right)$, and the adduct appears to arise directly from oxidized enzyme, anaerobically. Second, the rate of enzyme reduction cannot differ greatly from the inactivation rate. This conclusion follows from the low partition ratio. This number represents a ratio of the turnover rate to the inactivation rate and thus predicts that the limiting turnover rate for $\alpha \mathrm{HB}$ cannot be greater than $2.5 \mathrm{~min}^{-1}$. Since turnover with D-lactate by oxygen is about 50 times greater under these conditions (Olson \& Massey, 1979), this rate is likely to reflect the rate of reduction of the enzyme. In keeping with this conclusion, the rate of inactivation was not affected by the presence of oxygen (Figure 2).

Under anaerobic conditions, reduction of the enzyme by $\alpha \mathrm{HB}$ is a reversible process, as evidenced by the rapid oxidation of reduced enzyme by a slight excess of $\alpha \mathrm{KB}$. Comparison with the estimated rate of reduction by $\alpha \mathrm{HB}$ indicates that the rate of oxidation of reduced enzyme by $\alpha \mathrm{KB}$ is much faster than the rate of reduction of oxidized enzyme by $\alpha$ HB. Since the redox potentials for substrate and enzyme flavin are separated by nearly $100 \mathrm{mV}$, only a small fraction of the enzyme will ever accumulate in the reduced state. Thus, thermodynamic factors are probably responsible for the apparent formation of pink flavin from an oxidized enzyme species.

In summary, thermodynamic considerations probably dictate from which flavin redox state the flavin adduct will arise as with L-lactate oxidase, and thus this information provides no basis for distinguishing between the two alternative inactivation mechanisms. Further, although no rapid formation of pink 
flavin was observed when $\alpha \mathrm{KB}$ was generated in the presence of reduced enzyme, $\alpha \mathrm{KB}$ cannot be ruled out as the reactive species which adds to the flavin, since it is possible that a rapid equilibrium exists between the $\alpha \mathrm{HB}$-carbanion and $\alpha \mathrm{KB}-$ enzyme complexes. It thus appears that kinetic data cannot distinguish between these two possibilities.

On the other hand, chemical considerations which will be detailed in the following paper might give better clues as to which of the two plausible catalytic intermediates give rise to the pink flavin. One crucial finding is the lack of flavin modification observed when the enzyme is incubated anaerobically or allowed to turn over with $\alpha$-hydroxybutenoate. With this substrate, an inactivation of D-lactate dehydrogenase is observed which probably results from random alkylation of the protein as was observed similarly with L-amino acid oxidase (Marcotte \& Walsh, 1976) and the $E$. coli sugar transport protein component (Kaczorowski et al., 1975). The lack of modification of the flavin with $\alpha$-hydroxybutenoate vs. the formation of covalent flavin adducts with $\alpha \mathrm{HB}$ covalent flavin adducts with $\alpha \mathrm{HB}$ appears to be a constant property of all the flavoenzymes which oxidize $\alpha$-hydroxy acids (Walsh, 1977, 1978). It thus appears that a Michael-type addition from a reduced enzyme $-\alpha \mathrm{KB}$ complex is very improbable, although clearly such an event cannot be rigorously excluded.

Another important finding which bears promise in answering the question of mechanism is the trapping of an intermediate of the pink flavin in the presence of oxygen. The fact that two different types of flavin modification occur aerobically implies that an intermediate preceding pink flavin formation but occurring after $\alpha$-hydrogen abstraction must react with oxygen at a rate competitive with that of conversion to pink flavin. From its oxygen reactivity, this intermediate must have a structure related to or identical with 1,5-dihydroflavin; i.e., a substitution at positions $\mathrm{C}(4 \mathrm{a})$ or $\mathrm{N}(5)$ similar to that found with other known acetylenic inhibitors cannot have occurred. As discussed in the following paper, this intermediate from mechanistic considerations could be unique to the carbanion pathway (Ghisla et al., 1979).

So far, several $\alpha$-hydroxy acid oxidizing flavoenzymes have been reported to be inactivated by $\alpha \mathrm{HB}$, and in all cases the inactivation occurs by chemical modification of the flavin (Walsh, 1977). D-Lactate dehydrogenase provides yet another example but is unique among these flavoenzymes in the kind of chemical modification that takes place. The pink flavin formed by D-lactate dehydrogenase is an entirely new type of flavin adduct, differing markedly from the other two types of flavin "suicide" adducts which have been found (Schonbrunn et al., 1976; Maycock et al., 1976). Those $\alpha$-hydroxy acid oxidizing flavoenzymes for which spectral data have been published all appear to form adducts resembling that found with lactate oxidase (Lederer, 1974; Cromartie \& Walsh, 1975). The structural elucidation of the new adduct is detailed in the following paper (Ghisla et al., 1979).

\section{References}

Bessey, O. A., Lowry, O. H., \& Love, R. H. (1949) J. Biol. Chem. 180, 755-769.

Bloch, K. (1971) Enzymes, 3rd Ed. 5, 441.

Bright, H. J., \& Porter, D. J. (1975) Enzymes, 3rd Ed. 12, 421 .

Brockman, H. L. (1971) Ph.D. Thesis, Michigan State University, East Lansing, MI.

Brockman, H. L., \& Wood, W. A. (1975) J. Bacteriol. 124, 1454.

Cromartie, T. H., \& Walsh, C. (1975) Biochemistry 14, 3482.

Curti, B., Ronchi, S., Branzoli, U., Ferri, G., \& Williams, C. H., Jr. (1973) Biochim. Biophys. Acta 327, 266.

Ghisla, S., Ogata, H., Massey, V., Schonbrunn, A., Abeles, R. H., \& Walsh, C. T. (1976) Biochemistry 15, 1791.

Ghisla, S., Olson, S. T., Massey, V., \& Lhoste, J. M. (1979) Biochemistry (third of three papers in this issue).

Kaczorowski, G., Kaback, H. R., \& Walsh, C. (1975) Biochemistry 14, 3903.

Lederer, F. (1974) Eur. J. Biochem. 46, 393.

Leonard, N. J., Ed. (1956) Org. Synth. 36, 3.

Marcotte, P., \& Walsh, C. (1976) Biochemistry 15, 3070.

Marcotte, P., \& Walsh, C. (1978a) Biochemistry 17, 2864.

Marcotte, P., \& Walsh, C. (1978b) Biochemistry 17, 5613-5619.

Massey, V., \& Swoboda, B. E. P. (1963) Biochem. Z. 338, 474.

Massey, V., \& Curti, B. (1966) J. Biol. Chem. 241, 2347.

Massey, V., Curti, B., \& Ganther, H. (1966) J. Biol. Chem. $241,2347$.

Maycock, A. L., Abeles, R. H., Salach, J. I., \& Singer, T. P. (1976) Biochemistry 15, 114.

Mayhew, S. G. (1971) Biochim. Biophys. Acta 235, 289.

Mayhew, S. G., \& Massey, V. (1969) J. Biol. Chem. 244, 794.

Mayhew, S. G., \& Strating, M. J. J. (1975) Eur. J. Biochem. 59, 539.

McCormick, D. B., Chassy, B. M., \& Tsibris, J. C. M. (1964) Biochim. Biophys. Acta 89, 447.

Olson, S. T., \& Massey, V. (1979) Biochemistry (first of three papers in this issue).

Schonbrunn, A., Abeles, R. H., Walsh, C. T., Ghisla, S., Ogata, H., \& Massey, V. (1976) Biochemistry 15, 1798.

Shoemaker, C. P., \& Garland, C. W. (1962) Experiments in Physical Chemistry, 2nd ed., pp 17-37, McGraw-Hill, New York.

Verny, M., \& Vessiere, R. (1967) Bull. Soc. Chim. Fr., 2210.

Walsh, C. (1977) Horiz. Biochem. Biophys. 3, 36.

Walsh, C. (1978) Annu. Rev. Biochem. 47, 881.

Walsh, C. T., Schonbrunn, A., Lockridge, O., Massey, V., \& Abeles, R. H. (1972a) J. Biol. Chem. 247, 6004.

Walsh, C. T., Abeles, R. H., \& Kaback, H. R. (1972b) J. Biol. Chem. 247, 7858-7863. 